ticles. Next, he may have been misled by nurses and attendants. Thirdly, some apparently trifling circumstance may be neglected. Fourthly there may be something peculiar in the patient, the climate, or the season. In a word, every thing may be summed up in this plain and well known fact; that many articles are introduced into the world under very promising recommendations, and yet are soon neglected; and happy is it, if nothing mischievous has contributed to the decline of their reputation.

We have thus noticed some peculiarities in the management of ipecacuanha: but we have not treated of the history of this drug as an article of the materia medica, though somewhat curious; nor spoken of its various uses. These particulars arc left for the notice of other's.

\title{
A SINGULAR CASE OF OVARIAN DROPSY.
}

BY LYMAN SPALDING, M. D.

[For the New.England Journal of Medicine, \&c.

IN July, 1812, I was consulted by a faty of Portsmouth, NewHampshire, on account of an enlargement in the region of the right ovarium, accompanied with an œelematous swelling of the left foot and ankle.

From a critical examination of all the symptoms, I was convinced that the swelling was an ovarian dropsy; particularly as the other parts of the system were taking on dropsical action.

I made a careful examination of the intumescencc, in August; it was globular, smooth, and equable, without pain or liscolouration, and located in the precise region of the right ovarium. I was not satisfied that I could perceive any fluctuation. Occasionally a pain darted down the thigh in the course of the round ligament. At this time the cdematous swelling had affected the whole of the left leg, and was apparent in the right foot and ankle. The general health was not impaired, and the appetite and sleep were natural.

The examination, as well as every symptom and appearance, confirmed me in my opinion of the case being a dropsy of the ovarium. 
The high respectability of my patient, her aniable and endearing behaviour, her personal attachment, and the solicitude of her husband and firiends, all induced me to pay more than common attention to the case. I perused every author who had written on the disease; I detailed the symptoms and appearances to the physicians in the town; I submitted the case to many of my correspondents; and finally requested a consultation.

After much entreaty with the patient, who certainly possessed the most delicate and chaste mind of any lady whom 1 ever saw, she consented that doctor Pierrepont, of Portsmouth, should be called in consultation.

It was the final opinion * of the doctor, so far as I was made acquainted with it; and of all the other gentlemen, to whom I stated the case, that it was a dropsy of the ovarium.

The patient continued without any material alteration, but on the whole rather improving, till about the middle of November, (thanksgiving-day) when my benevolent patient was standing in a chair and reaching on to the highest shelf in a closet, to bestow her wonted charities to the poor, and nuaking an exertion to reach to an extreme height, she felt something give way sucldenly in the region of thetumour. She was obliged to sit down immediately and was very near fainting. When she rose up, she was astonished to find that the rotundity of the tumour had

* Doctor Pierrepont's opinion of the casc, as delivered in writing, to my friend and late pupil, Mr. W. L. Liungdon, after the death of the patient, is as follows :

“I can feel very little cloubt of Mrs. with scirrhus, although at my first visits for want of time to see the progress of the discase - from the want of a certrin freedom in first impressions which is gained by repeated interviews, I considered the case as a pure idi. opathic dropsy.

" My opinion now is that the dropsy was a sequel of scirrhus-that the ap. parent mpture of the ovarium might be that of a hydatid, that the apparent convalescence was merely a fleeting quiescence of morbid action, but that there was no real improvement of health, no diminution of disease. That there was not delivered to the physicians the precise history of phenomena, so that the pathognomic symptoms could be selected." 
Uisappeared, and that the contents were diffused uniformly through the cavity of the abdomen."

I saw her in this situation, but so satisfied was I of the nature of the case, not from my opinion alone, but from the concurrent testimony of all the gentlemen who were consulted; that it did not occur to me to examine for a fluctuation of water in the cavity of the abdomen. In fact, the present state of the case was so novel, being without a parallel, that my mind was wholly employed in investigating the issue of this new state of things.

My opinion, as delivered to my patient, was, that the ovarian sac had burst, and that the water was diffused through the cavity of the abdomen; that it would be absorbed, and the patient recover.

The patient wept on well, and there was every appearance in favour of the prediction being fulfilled.

The last of November, I removed from New-Hampshire to New-York, at which time the swelling caused by the diffusion of the water in the cavity of the abdomen had subsided; the swelling of the feet and legs had disappeared; there was neither pain, swelling, nor discolouration in the region of the ovarium; and the general health of the patient was rapidly mending.

In this state of the case, I did not hesitate to felicitate my patient on her wonderful recovery; which she considered as nearly complete, and expressed to me a hope that she should need no further redical aid ; but desired me to detail the case particularly to doctor Pierrepont, that he night be well acquainted with all the circumstances, if it should be necessary to conlsult him.

On taking leave of the family, the husband requested me to consult the doctors Warren of Boston, doctor Rush of Pliladelphia, and several of the most eminent physicians in New-York,

- Ioctor R. S. Kissam, of this town, informed me of a case of ovarian dropsy, of many years standing, in which no fluctuation was perceptible. 'The patient fell from a carriage, and burst the sac; the water was diffused through the cavity of the abdomen, and fluctuation was perfectly evident. He waited several weeks for absorption, but it did not take place. IIc then tapped her, and drew off twenty-six pints of bloody water. The patient re. covered. 
and transmit him their opinions. I did so; the doctors Warre had no hesitation in saying the case was dropsy of the ovarium. $\therefore$ It was not till February that I saw doctor Rush. He told me that doctor Pierrepont had written a statement of the case to hin, and that he had given his opinion, that it was dropsy of the ovarium.

But alas! how uncertain is every thing in this transitory world. Not long after I left New-Hampshire, a change took place in the nature of the disease; and my beloved patient, who was ondcared to the world by ten thousand tender charities, who had all the attacliments, which the best of husbands, agreeable family connexions, and wealth could bestow, and above all, who was fitted and prepared to enjoy this life, by a constant prepara. tion for a future, was doomed to suffer and die with a scirrhus of the uterine organs.

It is not at all extraordinary that this case should have changed from a dropsy of the ovarium to a scirrhus of the uterine organs; when we take into consideration, that there was an actual rupture of some part of the ovarium; and the great liability of that organ to scirrhous affections.

\section{CASE OF MALFORMATION OF HEART.}

BY ROBERT THAXTER, M. D.

[For the New-England Journal of Medicine, \&c.]

Tus subject of this case, a male, was at birth apparently well formed and healthy, and remained very well eight or ten days. At this time he was attacked with the ordinary symptoms of cold which continued a long time very troublesome. He became very emaciated, which was attributed partly to the above cause, and partly to the mother, whose health was at this time bad. He remained in this emaciated state till he was about a year old, at which time he began to grow corpulent, and continued so till his death; though his extremities were small compared with his body and head. As soon as he began to move much, he was obserwed to breathe with difficulty, and his countenance to become livid. Rest generally restored him to 